\title{
1030 DRUG SAFETY (PHARMACOVIGLANCE)
}

A M Olaitan* Correspondence to General Put-Patient Department, Ahmadu Bello University Teaching Hospital, Shika, Shika 234, Nigeria

\subsection{6/ip.2010.029215.1030}

Manifestation of adverse drug reactions are common occurrence in patients but poorly or never reported in our environment. They are common in antimalarial and antiretroviral drugs. Steven Johnson syndrome due to (sulpadoxine/pyrimethamine -SP) and erythema due to ACT (Artesunate/Amodiaquine)in antimalarial adverse drug reaction. The anti-retroviral adverse drug reactions include allergy, skin rash, hyperpigmentation of the palms, lipoatrophy, lipodystrophy, lipohypertrophy, dyslipidaemia/coronary heart disease and nausea. 